\title{
Erratum to: Biodegradability and ecotoxicity of commercially available geothermal heat transfer fluids
}

\author{
Andreas Tiehm ${ }^{1}$ Kathrin R. Schmidt ${ }^{1} \cdot$ Birgit Körner $^{1} \cdot$ Frank Sacher $^{1} \cdot$ Rachel Conrad $^{2} \cdot$ Henner Hollert $^{2}$
}

Published online: 9 May 2017

(c) Springer-Verlag Berlin Heidelberg 2017

\section{Erratum to:}

Grundwasser (2016)

DOI 10.1007/s00767-015-0311-y

The original version of this article unfortunately contained a mistake. The presentation of Fig. 2 was incorrect. The corrected figure is given below.

The online version of the original article can be found under doi: 10.1007/s00767-015-0311-y.

Andreas Tiehm

andreas.tiehm@tzw.de

Kathrin R. Schmidt

kathrin.schmidt@tzw.de

Birgit Körner

birgit.koerner@tzw.de

Frank Sacher

frank.sacher@tzw.de

Rachel Conrad

rachel.conrad@rwth-aachen.de

Henner Hollert

henner.hollert@bio5.rwth-aachen.de

1 DVGW-Technologiezentrum Wasser (TZW), Karlsruher

Straße 84, 76139 Karlsruhe, Germany

2 Department of Ecosystem Analysis, RWTH Aachen

University, Worringerweg 1, 52074 Aachen, Germany 

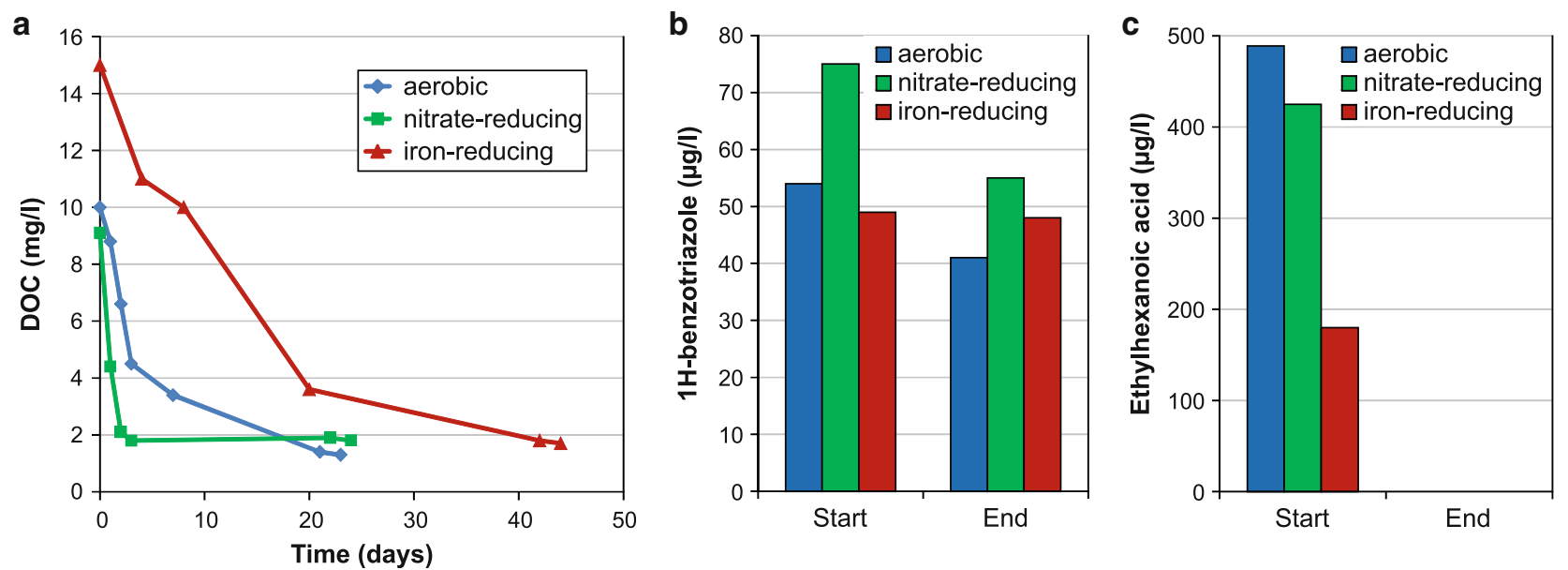

Fig. 2 Concentrations of (a) DOC (Dissolved Organic Carbon), (b) 1H-benzotriazole and (c) ethylhexanoic acid during fluid A biodegradation in groundwater at different redox conditions 